\title{
28 Research Square \\ Food Allergies in Iranian Patients With Migraine and Tension Headaches
}

\author{
Marzieh Heidarzadeh Arani \\ Kashan University of Medical Sciences \\ Ahmad Talebian \\ Kashan University of Medical Sciences \\ Hossein Akbari \\ Kashan University of Medical Sciences \\ Reihane Sharif \\ Kashan University of Medical Sciences \\ Alireza Ghannadian \\ Kashan university of medical sciences \\ Hossein Motedayyen ( $\sim$ hmotedayyen@gmail.com ) \\ Kashan University of Medical Sciences
}

\section{Research}

Keywords: Food allergies, Migraine headache, Tension headache

Posted Date: October 19th, 2021

DOl: https://doi.org/10.21203/rs.3.rs-962656/v1

License: (c) (i) This work is licensed under a Creative Commons Attribution 4.0 International License.

Read Full License 


\section{Abstract}

Background: Headache is one of the most common complaints of the nervous system around the world. Previous studies have proposed associations of food allergies with headaches. Therefore, this study evaluated the frequencies of food allergies in patients with migraine and tension headaches and their correlations with these disorders.

Methods: The study subjects comprised 40 patients with migraine and tension headaches. Headache disorders were diagnosed by a specialist and skin prick test (SPT) was performed to diagnosis food allergies in patients according to a standard technique.

Results: our data revealed no significant differences in age and gender between patients with migraine headache and tension headaches. Other results showed the frequencies of food allergies to egg, wheat, fish, banana, orange, and soybean in patients with migraine headache were similar to patients with migraine headache. However, patients with migraine headache significantly differed from those with tension headache in allergies to tree nut $(P=0.047)$, peanut $(P=0.028)$, and cow milk $(P=0.044)$.

Conclusion: The results of this study showed that some food allergies might be related to migraine headache which diagnosis of them can help to better control and treatment of disease.

\section{Background}

Headache is one of the most common complaints of the nervous system in childhood and adolescence. Its prevalence among school children is estimated as $10-20 \%$, which is increased up to $32 \%$ with the age increase at the age of 13-14 years (1). One of the most common headaches in children is migraine headaches which the average prevalence in children and adolescents is $9.1 \%$ (2). Migraine headache is mostly bilateral, pulsating which takes 4-72 hours and can be accompanied by vomiting, photophobia, and phono phobia (3).

Although the starting-based mechanisms of migraine attacks are not completely understood, activations of pain factors have key roles in promoting intracranial migraine pain (4). Immune cells with important roles in inflammation are vastly found in that area, including mast cells and granular immune cells (5). Allergens can stimulate the trigeminal nerve afferent fibers through releasing inflammatory mediators from dura mater mast cells (4). It is reported that released vasodilator substances and cytokines from mast cells and other immune cells have important roles in migraine's vasodilator phase and meningitis. Furthermore, IgE and histamine-mediated mechanisms may have some roles in the relation between allergy and migraine (6).

Although numerous studies have indicated associations between allergens and migraine, there are insufficient information and controversial results about these correlations. This matter indicates further studies are required in this field. This study was therefore focused on determining the frequencies of food 
allergies in patients with migraine headache differ from those with tension headache and their correlations to development of these headaches.

\section{Materials And Methods}

\section{Study populations}

The study subjects comprised 40 patients with migraine and tension headaches (aged 7 to 17 years) who were referred to the pediatric neurology clinic of Shahid Beheshti hospital, Kashan, Iran from September 2018 to March 2019. Headache disorders were diagnosed by a specialist according to the International Classification of Headache Disorders (ICHD-3) criteria (3). Exclusion criteria included: 1) patients with histories of allergy and chronic systemic diseases; 2) patients with positive skin prick test (SPT); 3 ) uses of $\mathrm{H}_{1}$ and $\mathrm{H}_{2}$ receptor blockers, steroids, anti-leukotrienes, and other anti-allergy medicines.

\section{Evaluation of food allergies}

SPT was performed by an allergy and immunology specialist in an allergy clinic. Some food allergens were used to diagnosis food allergies, including tree nut, peanut, wheat, soybean, cow's milk, fish, banana, orange, and egg extracts. All allergens were purchased from Stallergenes Greer (Antony Cedex, France). A standard dose of allergen extracts was used according to a standard technique (7). Briefly, a series of marks were made on the skin of the anterior part of the forearm after cleaning with $70 \%$ alcohol. A small drop of each allergen was placed on the skin and some scratches were gently made on the surface of the skin under each drop so that a small amount of the allergens penetrated into the skin. After 15 to 20 minutes, the results were read. Marked erythema with induration more than $3 \mathrm{~mm}$ diameter served as sensitive to allergens. Isotonic $\mathrm{NaCl}$ and histamine chloride mixed with $0.9 \%$ saline solution were used as negative and positive controls, respectively.

\section{Statistical Analysis}

Data were analyzed using SPSS (V. 19, IBM, Chicago, IL.) and are expressed as the mean \pm standard deviation (SD). Fisher's exact and Chi-square tests were used to evaluate the correlations. $p$ value $<0.05$ was considered statistically significant.

\section{Results}

As shown in Table 1, gender was not associated with headache $(P=0.752)$. Other results revealed no significant correlation between age and headache $(P=0.27)$. 
Table 1

Frequency of gender and mean of age in the studied groups

\begin{tabular}{|c|c|c|c|c|c|c|}
\hline \multirow[t]{2}{*}{ Headache Type } & \multicolumn{2}{|l|}{ Gender } & \multirow[t]{2}{*}{$P$ value* } & \multicolumn{2}{|l|}{ Age } & \multirow[t]{2}{*}{$P$ value $e^{\star \star}$} \\
\hline & male & female & & Mean & SD & \\
\hline Migraine & $10(50 \%)$ & $10(50 \%)$ & \multirow[t]{2}{*}{0.752} & 10.5 & 2.2 & \multirow[t]{2}{*}{0.27} \\
\hline Tension & $11(55 \%)$ & $9(45 \%)$ & & 11.4 & 2.8 & \\
\hline \multicolumn{7}{|c|}{${ }^{*}$ Pearson Chi-square test } \\
\hline${ }^{\star *}$ Independent sa & ples t-test & & & & & \\
\hline
\end{tabular}

Table 2

Frequency distributions of food allergies and their correlations with migraine and tension headaches

\begin{tabular}{|lllll|}
\hline \multirow{2}{*}{ Allergen } & \multicolumn{2}{l}{ Headache Type } & Total & P value* \\
\cline { 2 - 4 } & Migraine & Tension & & \\
\hline Orange & $3(15 \%)$ & $2(10 \%)$ & $5(12.5 \%)$ & 0.621 \\
\hline Banana & $4(20 \%)$ & $2(10 \%)$ & $6(15 \%)$ & 0.661 \\
\hline Fish & $5(25 \%)$ & $3(15 \%)$ & $8(15 \%)$ & 0.695 \\
\hline Cow's milk & $7(35 \%)$ & $1(5 \%)$ & $8(20 \%)$ & 0.044 \\
\hline Egg & $3(15 \%)$ & $1(5 \%)$ & $4(10 \%)$ & 0.605 \\
\hline Soybean & $6(30 \%)$ & $3(15 \%)$ & $9(22.5 \%)$ & 0.451 \\
\hline Tree nut & $5(25 \%)$ & $0(0 \%)$ & $5(12.5 \%)$ & 0.047 \\
\hline Peanut & $8(40 \%)$ & $2(10 \%)$ & $10(25 \%)$ & 0.028 \\
\hline Wheat & $4(20 \%)$ & $2(10 \%)$ & $6(15 \%)$ & 0.661 \\
\hline \multirow{2}{*}{ *The result of Fisher exact test } & & \\
\hline
\end{tabular}

The frequencies of food allergies and their associations with migraine and tension headaches

Our data revealed that food allergens such as orange, banana, fish, egg, soybean, and wheat were not significantly correlated to two types of headache (Table. 2). Other results showed that migraine headache was significantly associated with food allergies to cow's milk, tree nuts, and peanut $(P<0.05$, Table. 2$)$. However, there was no significant relationship between these food allergies and tension headache (Table. 2).

\section{Discussion}


Migraine headache is one of the most common headaches that involve approximately $15 \%$ of the population around the world. The etiology of this disorder is not well determined yet (6). It is shown that allergic reactions can participate in headaches through activating the trigeminal nerve afferent fibers (8). Therefore, we evaluated the frequencies of some food allergies in Iranian patients with migraine and tension headaches and their possible impacts in the developments of headaches.

The results of the present study revealed that there was no significant difference in skin allergies to egg, wheat, fish, banana, and soybean allergens between patients with migraine and tension headaches. However, patients with migraine headache had significantly higher skin allergies to peanut, cow's milk, and tree nut allergens than patients with tension headache.

Although there are few studies showing no significant impacts of food allergens on migraine development (9), the results of this study were consistent with numerous studies pointing to the effects of food allergies on the occurrence of migraine attacks (10-14) and they were in contrast with others indicating foods could be effective on both types of headaches $(15,16)$. Ku et al. reported that there was a significant difference in migraine prevalence between patients with and without allergic rhinitis (17). In a study conducted by Grant et al. it was demonstrated that some food allergies had fundamental roles in enhancing migraine attacks (10). The most prevalent of these allergens were wheat (78\%), orange (65\%), egg (45\%), tea and coffee (40\%), chocolate and milk (37\%), beef (35\%), corn (35\%), sugar (35\%), yeast (35\%), mushroom (35\%), and pear (28\%) (10). Monro et al. had similar results in regard to the impacts of food allergens on the occurrence of migraine attacks (18). Wilson et al., evaluated 20 patients with migraine and skin prick test revealed the most prevalent foodstuffs related to migraine headache were wine, cheese, and chocolate (19). Eross et al. revealed that the most common allergens caused headaches in $62 \%$ of the patients were grass or special trees $(13 \%)$, dust $(10 \%)$, particular foodstuffs $(7.7 \%)$, cat and dog hairs (5.1\%), and mold (2.6\%) (20). In another study on individuals with migraine, the most common food allergens which aggravated migraine were egg, cheese, cow's milk, wheat, tomato, casein, pork, and bean (21). In line with the effects of food allergens on headaches, it is shown that some food allergens like wheat increase the frequency of migraine but not its severity (22). Previous studies on the relationships of asthma and eczema with migraine revealed the increased risk of asthma occurrence in children whose mother had migraine or asthma but not for eczema (23). Other studies have indicated that the migraine in mothers was related to rhinitis in their children (24).

Regarding the fact that migraine headaches may related to the long-term activation of nociceptors, allergies may participate in migraine headaches through releasing cytokines and vasodilators from mast cells and other immune cells in dura mater and thereby lead to vessel vasodilation in central nerve system and activation of the trigeminal nerve afferent fibers $(4,6,25,26)$.

\section{Conclusion}

Taken together, the results of this study along with previous studies showed that some food allergies might be related to migraine headache which diagnosis of them can help to better control and treatment 
of disease. However, there are some limitations related to the present study, including evaluation of the impacts of other food allergens on migraine and tension headaches and the lack of an elimination diet including cow's milk, tree nut, and peanut to determine its impacts on treatments of migraine headache. Therefore, these limitations should be studied in future studies with larger sample sizes.

\section{Declarations}

\section{Availability of data and materials}

All data generated or analyzed during the study are included in this published article.

\section{Acknowledgments}

The authors thank all individuals who participated in this study.

\section{Competing interests}

The authors have no conflict of interest.

\section{Funding}

This study was supported by Kashan University of Medical Sciences (grant number: 98015).

\section{Ethics declarations}

The research was approved by the Ethics Committee of Kashan University of Medical Sciences (IR.KAUMS.MEDNT.REC.1398.020). The study was performed in compliance with the World Medical Association Declaration of Helsinki on Ethical Principles for Medical Research Involving Human Subjects. Written informed consent was obtained from the participants and parents/guardians of patients before entering the study.

\section{Author contributions}

Marzieh Heidarzadeh Arani and Alireza Ghannadian participated in the disease diagnosis, sample collections, and obtained funding for the work. Ahmad Talebian and Hossein Akbari participated in the design of some experiments and statistical analysis of the data. Reihane Sharif carried out some of the experiments. Hossein Motedayyen participated in the study design and drafted the manuscript. The authors read and approved the final version of manuscript.

\section{Consent to publish}

Consent to publish the data was obtained from participants prior to entering the study.

\section{References}


1. How $\mathrm{CH}$, Chan WS. Headaches in children. Singapore medical journal. 2014;55(3):128-30. quiz 31.

2. Wober-Bingol C. Epidemiology of migraine and headache in children and adolescents. Curr Pain Headache Rep. 2013;17(6):341.

3. Headache Classification Committee of the International Headache Society (IHS) The International Classification of Headache Disorders, 3rd edition. Cephalalgia: an international journal of headache. 2018;38(1):1-211.

4. Levy D, Burstein R, Kainz V, Jakubowski M, Strassman AM. Mast cell degranulation activates a pain pathway underlying migraine headache. Pain. 2007;130(1-2):166-76.

5. Artico M, Cavallotti C. Catecholaminergic and acetylcholine esterase containing nerves of cranial and spinal dura mater in humans and rodents. Microscopy research technique. 2001;53(3):212-20.

6. Lipton RB, Bigal ME. Migraine: epidemiology, impact, and risk factors for progression. Headache. 2005;45(Suppl 1):3-s13.

7. Dreborg S. Skin tests used in type I allergy testing. Position Paper. Sub Committee O. Skin Tests of the European Academy of Allergology and Clinical Immunology. Allergy. 1989;10:1-59.

8. Artico M, Cavallotti C. Catecholaminergic and acetylcholine esterase containing nerves of cranial and spinal dura mater in humans and rodents. Microscopy research technique. 2001;53(3):212-20.

9. Pradalier A, Weinman S, Launay JM, Baron JF, Dry J. Total IgE, specific IgE and prick-tests against foods in common migraine-a prospective study. Cephalalgia: an international journal of headache. 1983;3(4):231-4.

10. Grant EG. Food allergies and migraine. The Lancet. 1979;313(8123):966-9.

11. Sillanpää M, Aro H. Headache in teenagers: comorbidity and prognosis. Functional neurology. 2000;15:116-21.

12. Davey G, Sedgwick P, Maier W, Visick G, Strachan DP, Anderson HR. Association between migraine and asthma: matched case-control study. Br J Gen Pract. 2002;52(482):723-7.

13. Artto V, Wessman M, Nissilä M, Säkö E, Liukkonen J, Teirmaa H, et al. Comorbidity in Finnish migraine families. J Headache Pain. 2006;7(5):324-30.

14. Constantinides V, Anagnostou E, Bougea A, Paraskevas G, Kapaki E, Evdokimidis I, et al. Migraine and tension-type headache triggers in a Greek population. Arq Neuropsiquiatr. 2015;73(8):665-9.

15. Savi L, Rainero I, Valfre W, Gentile S, Lo Giudice R, Pinessi L. Food and headache attacks. A comparison of patients with migraine and tension-type headache. Panminerva medica. 2002;44(1):27-31.

16. Milde-Busch A, Blaschek A, Borggräfe I, Heinen F, Straube A, Von Kries R. Associations of diet and lifestyle with headache in high-school students: Results from a cross-sectional study. Headache: The Journal of Head Face Pain. 2010;50(7):1104-14.

17. Ku M, Silverman B, Prifti N, Ying W, Persaud Y, Schneider A. Prevalence of migraine headaches in patients with allergic rhinitis. Annals of allergy, asthma \& immunology: official publication of the American College of Allergy. Asthma Immunology. 2006;97(2):226-30. 
18. Monro J, Brostoff J, Carini C, Zilkha K. Food allergy in migraine. Study of dietary exclusion and RAST. Lancet. 1980;2(8184):1-4.

19. Wilson CW, Kirker JG, Warnes H, O'Malley M. The clinical features of migraine as a manifestation of allergic disease. Postgraduate medical journal. 1980;56(659):617-21.

20. Eross E, Dodick D, Eross M. The Sinus, Allergy and Migraine Study (SAMS). Headache. 2007;47(2):213-24.

21. Arroyave Hernandez CM, Echavarria Pinto M, Hernandez Montiel HL. Food allergy mediated by IgG antibodies associated with migraine in adults. Revista alergia Mexico (Tecamachalco, Puebla, Mexico: 1993). 2007;54(5):162-8.

22. Bektas $H$, Karabulut $H$, Doganay $B, A c a r ~ B$. Allergens might trigger migraine attacks. Acta Neurol Belgica. 2017;117(1):91-5.

23. Chen TC, Leviton A. Asthma and eczema in children born to women with migraine. Arch Neurol. 1990;47(11):1227-30.

24. Mortimer MJ, Kay J, Gawkrodger DJ, Jaron A, Barker DC. The prevalence of headache and migraine in atopic children: an epidemiological study in general practice. Headache. 1993;33(8):427-31.

25. Buzzi MG, Dimitriadou V, Theoharides TC, Moskowitz MA. 5-Hydroxytryptamine receptor agonists for the abortive treatment of vascular headaches block mast cell, endothelial and platelet activation within the rat dura mater after trigeminal stimulation. Brain research. 1992;583(1-2):137-49.

26. Meggs WJ. Neurogenic switching: a hypothesis for a mechanism for shifting the site of inflammation in allergy and chemical sensitivity. Environmental health perspectives. 1995;103(1):54-6. 